\title{
Inhibiting the role of Skp2 suppresses cell proliferation and tumorigenesis of human gastric cancer cells via the upregulation of $\mathbf{p} 27^{\mathrm{kip} 1}$
}

\author{
YANGUANG WEN ${ }^{1}$, KUANSONG WANG ${ }^{2,3}$ and KAIYAN YANG ${ }^{1}$ \\ ${ }^{1}$ Department of The Second General Surgery, Third Xiangya Hospital, Xiangya School of Medicine, Central South University, \\ Changsha, Hunan 410013; ${ }^{2}$ Department of Pathology, Xiangya Hospital, Central South University, Changsha, Hunan 410008; \\ ${ }^{3}$ Department of Pathology, Basic Medical School, Central South University, Changsha, Hunan 410013, P.R. China
}

Received July 26, 2015; Accepted May 31, 2016

DOI: $10.3892 / \mathrm{mmr} .2016 .5676$

\begin{abstract}
Gastric cancer is a malignant disease of the digestive system with high rates of incidence and mortality. S-phase kinase-associated protein 2 (Skp2) is a novel oncogene, which has been identified to be important in tumor progression and metastasis. In order to clarify the role of Skp2 in human gastric cancer, the present study detected the expression of Skp2 in human gastric cancer tissues, and investigated the molecular mechanism of Skp2 in the progression of gastric carcinoma. The results of the initial bioinformatics analysis showed that Skp2 was significantly upregulated in 31 specimens of primary gastric cancer from a UK patient cohort, and in 10 gastric cancer lines of a side population, compared with normal gastric tissues $(\mathrm{P}<0.01)$. Specimens from 47 patients with gastric cancer and 19 normal gastric tissue specimens were obtained and analyzed using western blot analysis. The positive rate of expression of Skp2 was $87.2 \%$, indicating that the expression of Skp2 was observed in 41 specimens of the detected gastric cancer samples, whereas the positive rate of the expression of Skp2 was $5.6 \%$ in the normal gastric samples $(\mathrm{P}<0.01)$. In the human gastric cancer cell lines, the defective regulation of Skp2 or presence of an Skp2 inhibitor inhibited the proliferation of BGC-823 and MKN-45 cells. In addition, the Skp2 inhibitor suppressed the proliferation of gastric cancer cells in a time- and dose-dependent manner. Furthermore, transfection with Skp2 short hairpin (sh)RNA or treatment with SKP inhibitor $\mathrm{C} 1$ for 48 and $72 \mathrm{~h}$ led to the accumulation of $\mathrm{p} 27^{\mathrm{kip} 1}$ in Hela cells. Tumorigenicity experiments involving nude mice showed that interference of the expression of Skp2 inhibited
\end{abstract}

Correspondence to: Professor Kaiyan Yang, Department of The Second General Surgery, Third Xiangya Hospital, Xiangya School of Medicine, Central South University, 138 Tongzipo Road, Changsha, Hunan 410013, P.R. China

E-mail: yangkaiyanky@hotmail.com

Key words: gastric cancer, S-phase kinase-associated protein 2, S-phase kinase-associated protein 2 inhibitor, tumor weight the growth of the human gastric tumor cells in the nude mice, and the tumor weights and volumes in the Skp2 shRNA group were significantly lower, compared with those in the negative control shRNA group $(\mathrm{P}<0.01)$ and untreated group $(\mathrm{P}<0.01)$. Taken together, these data suggested that Skp2 acted as an oncogene in human gastric cancer, and that Skp2-mediated p2 $7^{\mathrm{kip} 1}$ degradation contributed to the progression of gastric cancer. Abrogating the effects of Skp2 may effectively inhibit the growth of gastric cancer cells, which may be useful as a novel target in the clinical treatment of gastric cancer.

\section{Introduction}

Gastric cancer is a malignant disease of the digestive system; it has a high incidence rate and is the second leading cause of cancer-associated mortality worldwide (1). The clinical symptoms in the early stage are not obvious, and predominantly include upper abdominal pain, heartburn, nausea and loss of appetite $(2,3)$. Currently, radical gastrectomy is the predominant treatment method for patients with early stage disease. The curative effects are satisfactory, with a 5-year survival rate of $>90 \%(4,5)$. However, the majority of patients are diagnosed at an advantage stage, which limits the opportunities for radical surgery, and the overall 5-year survival rate is only $~ 30 \%(6,7)$. Later symptoms include yellow skin, vomiting, weight loss and the presence of blood in the stools. Several studies have found that gastric cancer is a multistage pathological state, and environmental factors, particularly improper dietary habits, are considered to be important in the development of gastric cancer (8-12). At present, the pathogenesis of gastric cancer remains to be fully elucidated. Therefore, it is important for gastric cancer prevention to investigate the pathogenesis of gastric cancer, and identify novel tumor markers for early diagnosis, prediction and prognosis of recurrence.

Following further developments in the molecular biology of gastric cancer, novel targets, which are associated with tumor cell growth, apoptosis, cell cycle, and the invasion and infiltration of gastric cancer have become the focus of interest in the investigation of gastric cancer. Cell cycle abnormalities i are usually found in tumorigenesis and tumor progression. The cell cycle is tightly regulated by cyclin-dependent kinases (CDKs), cyclines 
and CDK inhibitors (13). The degradation of these regulatory proteins is mediated and regulated by the ubiquitin-proteasome system. S-phase kinase-associated protein 2 (Skp2) is the substrate of E3 ligases and is involved in the recruiting component of the SCFSkp2 complex. Skp2 is important for inducing the degradation of CDK inhibitors, including $\mathrm{p} 21^{\mathrm{cip} 1}, \mathrm{p} 27^{\mathrm{kip} 1}$ and $\mathrm{p} 57^{\mathrm{kip} 2}(14-16)$. It is commonly observed in numerous types of human cancer, and is important in tumor progression and metastasis $(17,18)$. In salivary malignancies, significant correlations have been found between survival rates and the expression levels of Skp2, p27 and p53, demonstrating that Skp2 is important in the pathogenesis of salivary cancer (19). In patients with advanced prostate cancer, Skp2 has been found to regulate androgen receptors through ubiquitin-mediated degradation, independent of $\mathrm{Akt} / \mathrm{mammalian}$ target of rapamycin pathways in prostate cancer cells (20). Davidovich et al (21) found that the overexpression of Skp2 was associated with resistance to chemotherapeutic drugs. In patients with locally advanced breast cancer, Skp2 has been used as a diagnostic marker for predicting the response to doxorubicin-based preoperative chemotherapy and clinical outcome. The inhibition of Skp2 offers a potential strategy to suppress tumorigenesis in cases where tumor suppressor genes, including retinoblastoma and tumor protein P53 are mutated $(22,23)$.

However, the molecular mechanism underlying the expression of Skp2 during the progression of gastric cancer remains to be fully elucidated. In the present study, the role of Skp2 in patients with gastric cancer was further clarified, and the molecular mechanisms were examined using in vitro and in vivo experiments. These investigations may provide novel clues for the clinical treatment of human gastric cancer.

\section{Materials and methods}

Patients. A total of 66 tissue specimens were collected from the Third Xiangya Hospital (Changsha, China) in the present study, including 47 gastric cancer tissue specimens (21 female and 26 male) and 19 normal gastric tissue specimens (8 female and 11 male). The median age of the patients was 48.67 years (range, 26-84 years), and the samples were collected between September 2013 and September 2015. The specimens were stored at $-80^{\circ} \mathrm{C}$ and used for western blot analysis. The human investigations in the present study were performed in compliance with the Declaration of Helsinki. Approval for the study was obtained from the Ethics Committee of Third Xiangya Hospital. The patients were well informed of the details and signed relevant consent forms prior to commencement of the investigation The experiments using mice in the present study were performed in accordance with Animal Ethical Care (24,25).

Cell lines and reagents. The BGC-823 and MKN-45 gastric cancer cell lines were obtained from Shanghai Institute of Materia Medica, Chinese Academy of Tumor Cell Bank (Shanghai, China). The cells were cultured at $37^{\circ} \mathrm{C}$ and $5 \% \mathrm{CO}_{2}$ in Dulbecco's modified Eagle's medium (DMEM) with $10 \%$ fetal bovine serum (GE Healthcare Life Sciences, Logan, UT, USA), $1 \%$ penicillin and 1\% streptomycin. Skp2 inhibitor C1 (SKPin C1) was purchased from MedChem Express (Princeton, NJ, USA). A purified recombinant protein of human $445 \mathrm{Skp} 2$, transcript variant 1 with an N-terminal
His tag, expressed in Escherichia coli $(50 \mu \mathrm{g})$, was obtained from OriGene Technologies (Beijing, China). MTT reagent was obtained from Sigma-Aldrich (St. Louis, MO, USA). The human Skp2 short hairpin (sh)RNA, four unique 29-mer shRNA constructs in the retroviral green fluorescent protein (GFP) vector, and the non-effective 29-mer scrambled shRNA cassette in the pGFP-V-RS vector were obtained from OriGene Technologies. Bioinformatics analysis was conducted using the BioGPS gene annotation portal (http://biogps.org/).

Western blot analysis. The cells were lysed with radioimmunoprecipitation assay lysis buffer (P0013B), which was obtained from Beyotime Institute of Biotechnology (Haimen, China). The proteins in the lysates were separated by $10 \%$ polyacrylamide gel electrophoresis, which was prepared in house including a stacking gel and a separating gel. The proteins were loaded on a polyvinylidene difluoride membrane. The antibodies used in the experiments were as follows: Rabbit polyclonal anti-Skp2 antibody (1:1,000; cat. no. 15010-1-AP) was obtained from ProteinTech Group, Inc. (Wuhan, China). Rabbit polyclonal anti-p27 ${ }^{\mathrm{kip} 1}$ antibody $(1: 1,000$; cat. no. ab137736) was purchased from Abcam (Cambridge, MA, USA). Rabbit polyclonal anti- $\beta$-actin antibody $(1: 1,000$; cat. no. sc-7210) and horseradish peroxidase-conjugated goat anti-rabbit secondary antibody (sc-2030) were obtained from Santa Cruz Biotechnology, Inc. (Dallas, TX, USA). The blots were visualized using the GelDoc XR system (Bio-Rad Laboratories, Inc., Hercules, CA, USA) and Quantity One 1-D analysis software, version 4.6.9 (Bio-Rad Laboratories, Inc.).

MTT assay. The cell survival rate and proliferation were determined using an MTT assay, as described (26,27). In brief, the BGC-823 cells and MKN-45 cells were plated into 48-well plates at 1,000 cells/well, and the cells were transfected with Skp2-specific shRNA or negative control (N.C.) shRNA using Lipofectamine 2000 for 24, 48, 72 and $96 \mathrm{~h}$, respectively, at room temperature. At $4 \mathrm{~h}$ prior to analysis, $5 \mathrm{mg} / \mathrm{ml}$ of MTT was added into the medium. Finally, the purple crystals was dissolved with DMSO, and the data were analyzed at a test wavelength of $490 \mathrm{~nm}$.

For Skp2 inhibition, the human gastric cancer cells were plated into 96 -well plates at 1,000 cells/well at $37^{\circ} \mathrm{C}$ with $5 \%$ $\mathrm{CO}_{2}$. After $6 \mathrm{~h}$, the BGC-823 cells and MKN-45 cells were treated with SKPin $\mathrm{C} 1$ at concentrations of 1,5 and $10 \mu \mathrm{M}$ for $48 \mathrm{~h}$, and with $5 \mu \mathrm{M}$ SKPin $\mathrm{C} 1$ for 24,48 and $72 \mathrm{~h}$. The other steps were as described above.

Animal groups and tumor challenge. A total of 30 (10/group) C57BL/6 male nude mice (6-8 week-old; 18-20 g) were obtained from the Si Lai Ke Jing Da Laboratory Animal Co., Ltd. (Changsha, China). The mice were randomly divided into three groups and maintained in specific pathogen-free conditions at $22^{\circ} \mathrm{C}$ under a $12 / 12 \mathrm{~h}$ light/dark cycle with free access to food and water. The mice were challenged subcutaneously in the flank area with $5 \times 10^{5}$ BGC-823 tumor cells, BGC-823 cells transfected with Skp2 shRNA or BGC-823 cells transfected with N.C. shRNA. The tumor volumes were recorded every 3 days. At 30 days post-tumor injection, the mice were sacrificed by cervical dislocation and the tumor were weighed. Each group contained $>10$ mice. 


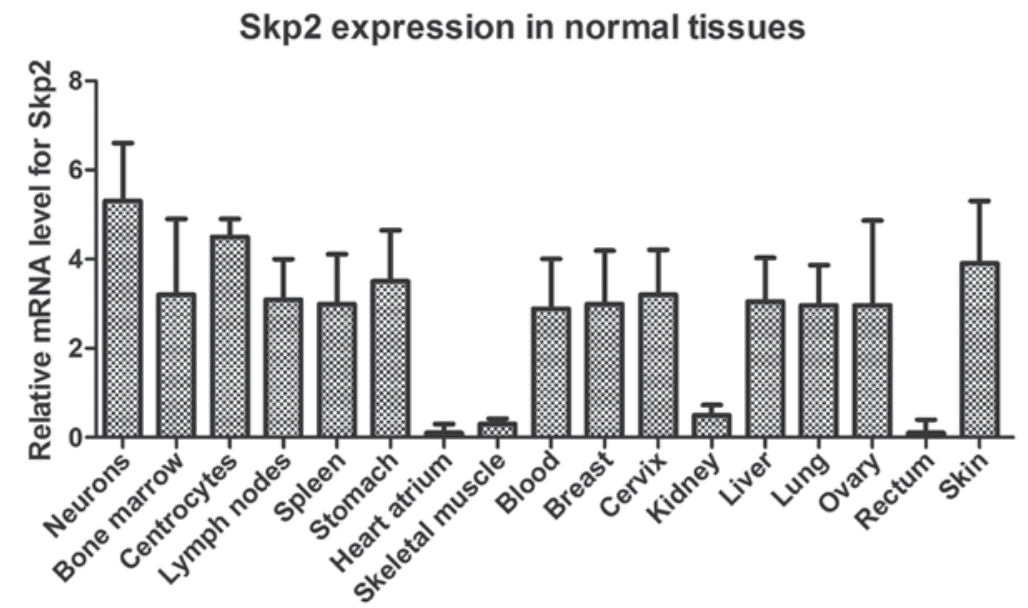

Figure 1. Expression levels of Skp2 in normal human tissues and organs. The arrows indicate the expression of Skp2 in the normal human stomach. Data are expressed as the mean \pm standard deviation. Skp2, S-phase kinase-associated protein 2.

A

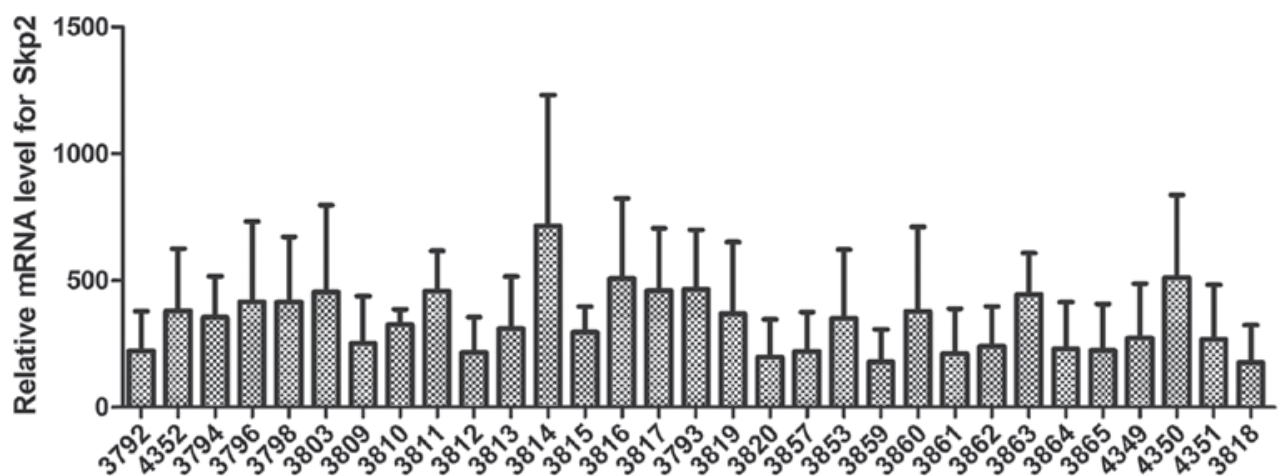

31 primary gastric tumors from the UK patient cohort

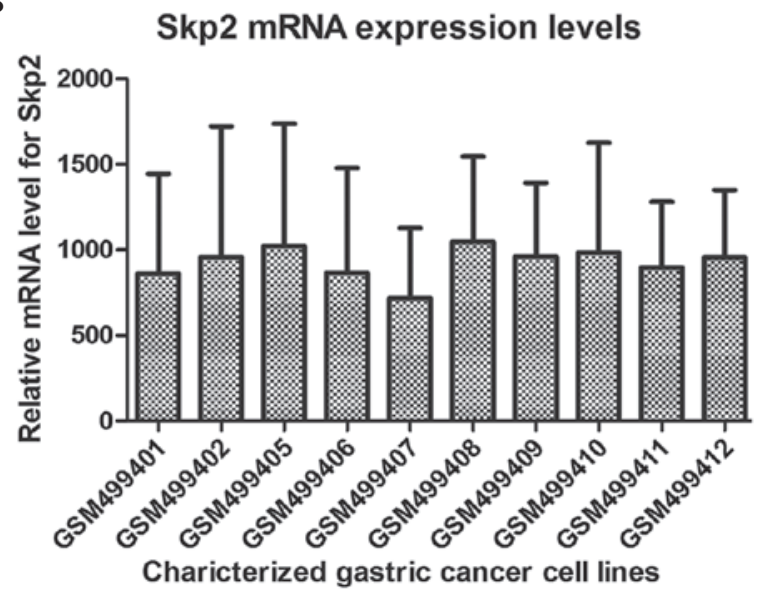

$\mathbf{C}$

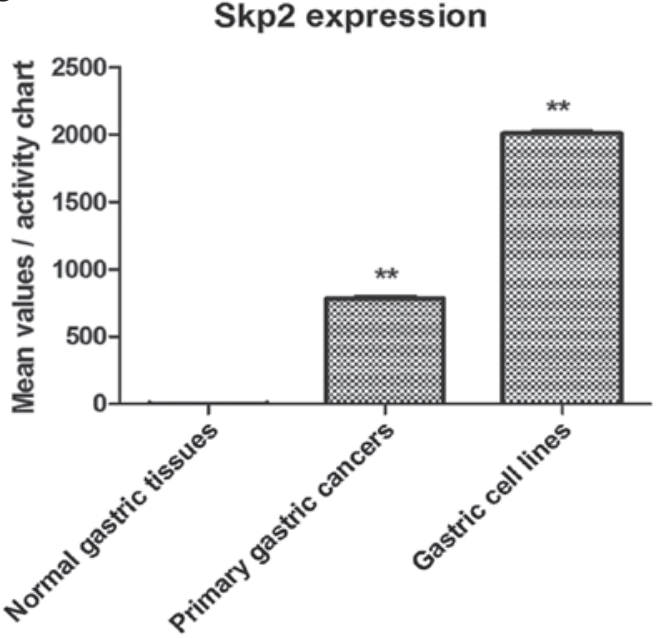

Figure 2. mRNA expression levels of Skp2 in gastric cancer cells, determined using bioinformatics analysis. (A) mRNA expression profiles of Skp2 in 31 primary gastric tumor tissue specimens from a UK patient cohort. (B) mRNA expression of Skp2 in side populations of gastric cancer cell lines with definite genotypic and phenotypic characterization. (C) Histogram of the mRNA expression levels of Skp2 in normal gastric tissues, primary gastric cancer tissues and identified gastric cell lines. Data are expressed as the mean \pm standard deviation. ${ }^{* *} \mathrm{P}<0.01$, compared with the normal gastric tissues. Skp2, S-phase kinase-associated protein 2.

Statistical analysis. The data in the present study were analyzed using SPSS software (SPSS, Inc., Chicago, IL, USA). Student's $t$-tests were used to evaluate statistical significance.
Data are expressed as the mean \pm standard deviation. $\mathrm{P}<0.05$ was considered to indicate a statistically significant difference. 


\section{Results}

Expression levels of Skp2 in normal tissues, primary gastric cancer tissues and gastric cancer cell lines, determined using the BioGPS platform. In order to determine the association between the expression of Skp2 and the progression of human gastric cancer, the presents study used bioinformatics methods to analyze the expression of Skp2 in the gastric tissues. BioGPS is a centralized gene portal for aggregating distributed gene annotation resources (28). The expression levels of Skp2 in the normal tissues, primary gastric cancer tissues and gastric cancer cell lines were readily and directly compared with each other. As shown in Figs. 1 and 2, the mean relative expression of Skp2 in the normal gastric tissues was 3.50, however, the mean values were 772 and 2,001.8 in the 31 primary gastric tumor tissues from the UK patient cohort and 10 gastric cancer cell lines of the side population, respectively. These data demonstrated that Skp2 was significantly upregulated in the primary gastric cancer tissues and gastric cancer lines, and that Skp2 may be an oncogene in the progression of gastric cancer.

Higher expression of Skp2 correlates with lower expression of p2 $7^{k i p l}$ in gastric cancer tissues. In order to confirm the results of the bioinformatics analysis, tissue specimens from patients with gastric cancer and the specimens of normal gastric tissues were collected. Western blot analysis was used to determine the expression levels of Skp2 and p27 $7^{\mathrm{kip} 1}$, as degradation of the tumor suppressor, $\mathrm{p} 27^{\mathrm{kip} 1}$, is mediated by Skp2. In the present study, the data were normalized to the level of $\beta$-actin, followed by analysis using Student's $t$-test and presentation of data as the mean \pm standard deviation. As shown in Fig. 3, three independent samples were used to detect the expression levels of Skp2 and p27 $7^{\mathrm{kip} 1}$, and the results demonstrated that the expression levels of Skp2 in the gastric cancer tissues were significantly increased, compared with those in the normal gastric tissues. However, the expression levels of $\mathrm{p} 27^{\mathrm{kip} 1}$ were inversely correlated with the levels of Skp2.

As shown in Table I, the expression levels of Skp2 in tissue specimens from 47 patients with gastric cancer and 19 normal gastric tissue specimens were assessed and analyzed using western blot analysis. Positive expression of Skp2 was observed in 41 specimens $(87.2 \%)$ of the gastric cancer samples, whereas the positive rate of expression was $5.6 \%$ in the normal gastric tissue samples $(\mathrm{P}<0.01)$. The results were consistent with those of the bioinformatics analysis.

Defective regulation of $S k p 2$ or the presence of Skp2 inhibitor contribute to decreased proliferation in human gastric cancer cell lines. In order to determine whether inhibiting the expression of Skp2 affects the proliferation of human gastric cancer cells, the present study used Skp2-specific shRNA to interfere with the endogenous expression of Skp2. As shown in Fig. 4A, the human gastric cancer cells were transfected with Skp2 shRNA and cultured for 24, 48, 72 and $96 \mathrm{~h}$, respectively. The subsequent MTT assay showed that the Skp2 shRNA-transfected cells had significantly lower survival rates, compared with the cells transfected with the N.C. shRNA. By contrast, the administration of recombinant Skp2 protein at a concentration of $0.1 \mu \mathrm{g} / \mathrm{ml}$ promoted
Table I. Protein expression of Skp2 in gastric carcinoma tissues and normal gastric tissues.

\begin{tabular}{lrrrr}
\hline & \multicolumn{3}{c}{ Skp2 } & \\
Tissue & $\mathrm{n}$ & + & - & Positive rate (\%) \\
\hline Normal gastric & 19 & 1 & 18 & 5.6 \\
Gastric cancer & 47 & 41 & 6 & $87.2^{\mathrm{a}}$ \\
\hline
\end{tabular}

${ }^{\mathrm{a}} \mathrm{P}<0.01$, compared with the normal gastric tissues. Skp2, S-phase kinase-associated protein 2 .

A

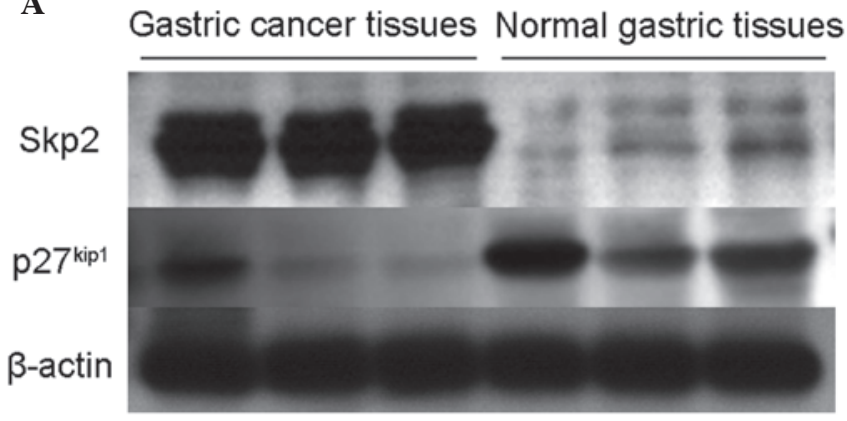

B
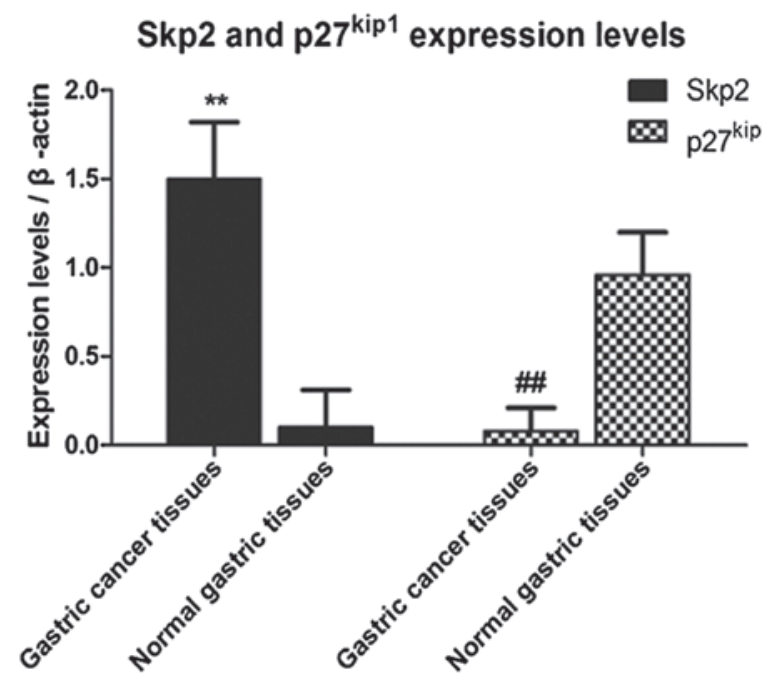

Figure 3. Higher expression of Skp2 correlates with lower expression of p27kip1 in gastric cancer tissues. (A) Specimens of malignant gastric cancer tissues and normal control gastric tissues were collected, and the lysates were used for detection of the expression of Skp2 and p2 $7^{\mathrm{kip} 1}$ using western blot analysis. $\beta$-actin was used as an internal reference, and the data are representative of three independent samples. (B) Expression levels of Skp2 and p27 are shown in the histogram. Images of the bands from the western blot analysis were captured and analyzed using Image $J$ software. The data were normalized to the levels of $\beta$-actin and are expressed as the mean \pm standard deviation. ${ }^{* *} \mathrm{P}<0.01$, compared with the normal gastric tissues. Skp2, S-phase kinase-associated protein 2.

the proliferation of the BGC-823 cells and MKN-45 cells, although no statistically significant difference was found between the recombinant Skp2-treated cells and the untreated gastric cancer cells.

Skp2 inhibitor inhibits the proliferation of gastric cancer cells in a dose-dependent manner. In order to confirm the role of 
A

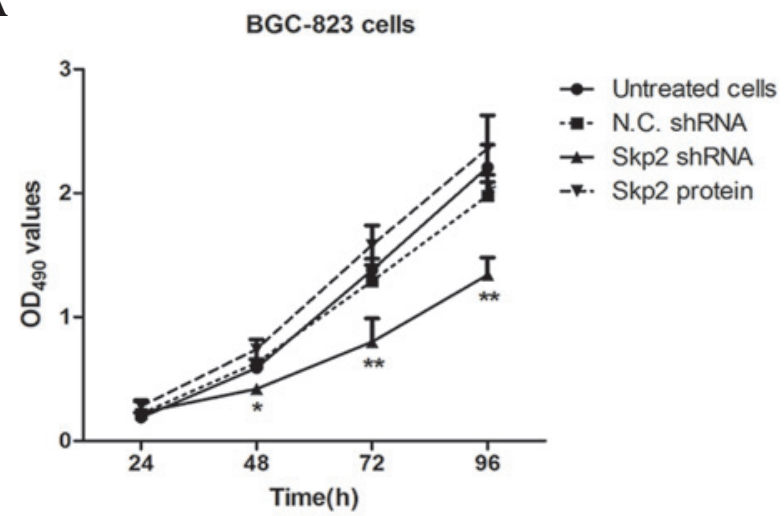

B

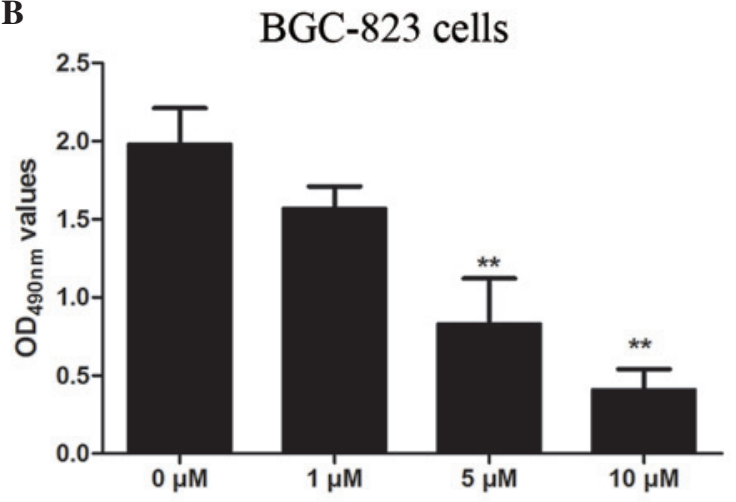

Concentration of SKPin C1

C

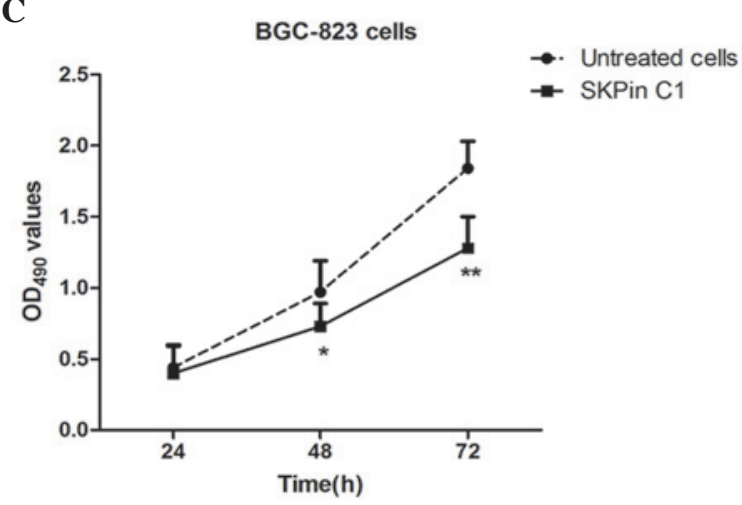

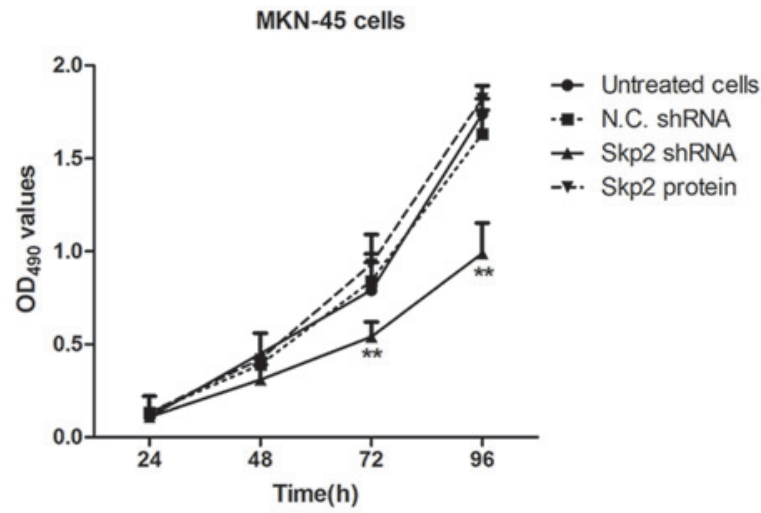

MKN-45 cells

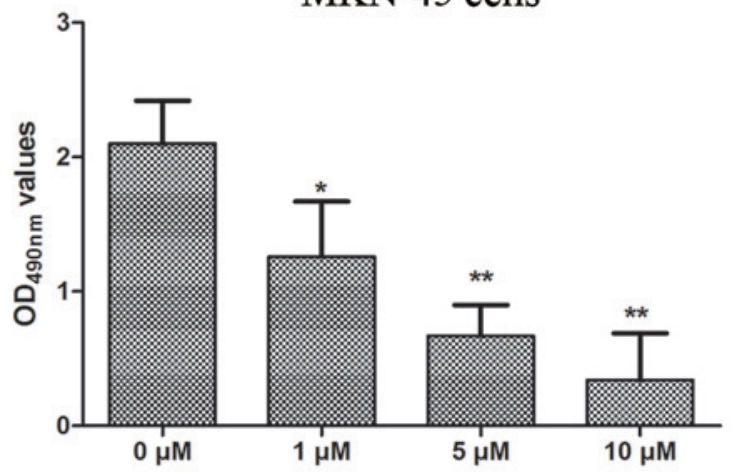

Concentration of SKPin C1

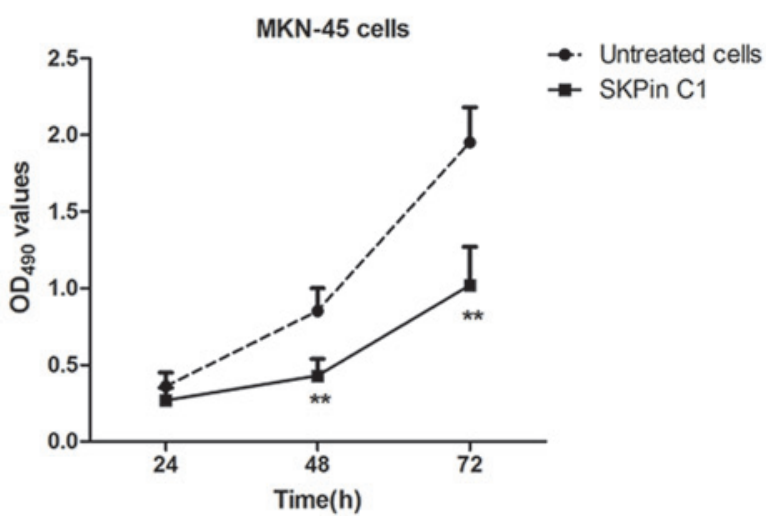

Figure 4. Defective regulation of Skp2 or Skp2 inhibition contributes to lower proliferation of human gastric cancer cell lines. (A) Interference with endogenous Skp2 inhibited human gastric cancer cells. BGC-823 and MKN-45 cells were transfected with Skp2 shRNA or N.C. shRNA, or administered with recombinant Skp2 protein for the indicated periods of time. An MTT assay was used to detect the proliferation of the BGC-823 and MKN-45 cells ("P<0.05 and $\left.{ }^{* *} \mathrm{P}<0.01\right)$ (B) Skp2 inhibitor inhibited the proliferation of gastric cancer cells in a dose-dependent manner. The BGC-823 and MKN-45 human gastric cancer cells were treated with increasing concentrations of SKPin C1 $(1,5$ and $10 \mu \mathrm{M})$ for $48 \mathrm{~h}$, and the survival rates were determined using an MTT assay. (C) Treatment with the Skp2 inhibitor contributed to the lower survival rates of the gastric cancer cells in a time-dependent manner. The gastric cancer cells were treated with $5 \mu \mathrm{M}$ SKPin $\mathrm{C} 1$ for 24,48 and $72 \mathrm{~h}$, respectively. The cell proliferation was determined using an MTT assay ("P $<0.05$ and ${ }^{* *} \mathrm{P}<0.01$, compared with the untreated cells). Data are expressed as the mean \pm standard deviation. Skp2, S-phase kinase-associated protein 2; SKPin C1, Skp2 inhibitor C1; shRNA, short hairpin RNA; N.C., negative control; OD, optical density.

Skp2 in the proliferation of human gastric cancer cells, an Skp2 inhibitor was to treat the BGC-823 cells and MKN-45 cells. SKPin C1 is a potent inhibitor of Skp2, and selectively inhibits Skp2-mediated p27 ${ }^{\text {kipl }}$ degradation by targeting the SCF-Skp2 protein-protein interface. As shown in Fig. 4B, the BGC-823 cells and MKN-45 cells were treated with increasing concentrations of SKPin C1 for $48 \mathrm{~h}$. The subsequent MTT assay results demonstrated that, as the concentrations of the Skp2 inhibitor increased, the survival rate of the human gastric cancer cells decreased significantly, compared with that of the untreated cells.

Treatment with Skp2 inhibitor contributes to lower survival rates of gastric cancer cells in a time-dependent manner. To 
A

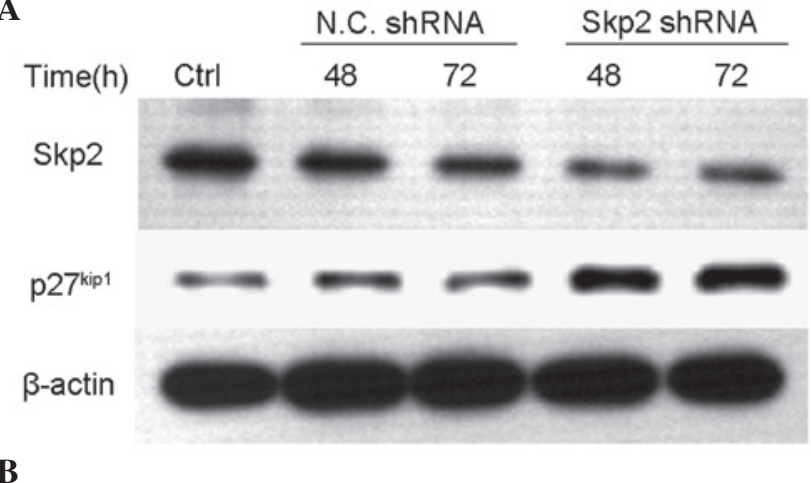

B

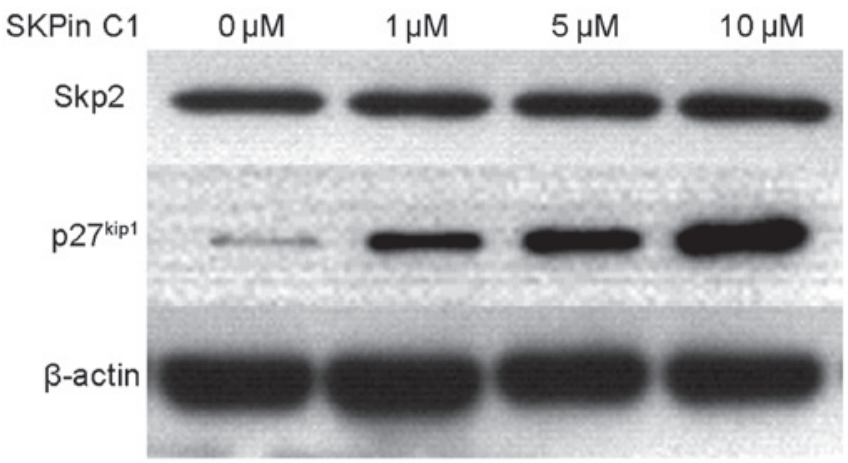

C

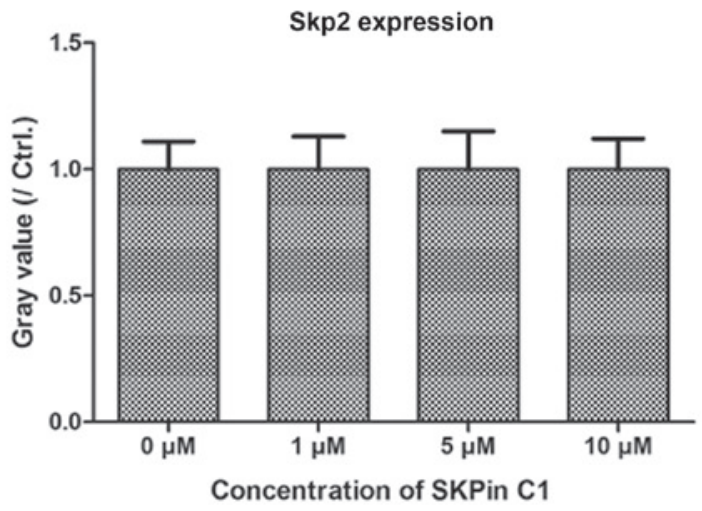

D

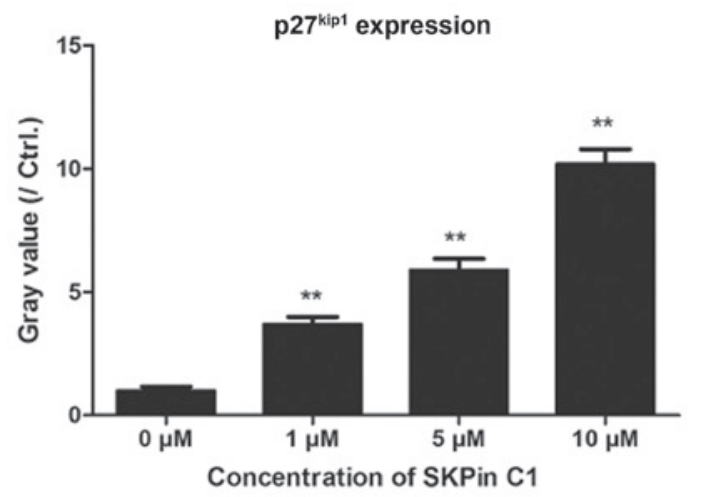

Figure 5. Transfection with Skp2 shRNA or treatment with SKPin C1 contributes to the accumulation of p27kip1 in human gastric cancer cells. (A) BGC- 823 cells $\left(5 \times 10^{5}\right.$ cells/well) were plated into 48 well plates. Following culture for $6 \mathrm{~h}$, the cells were transfected with Skp2 shRNA and N.C. shRNA. The cells were then cultured for 48 and $72 \mathrm{~h}$, and cell lysates were prepared. The expression levels of Skp2 and p2 $7^{\mathrm{kipl}}$ were determined using western blot analysis. (B) BGC-823 human gastric cancer cells $\left(3 \times 10^{5}\right.$ cells/well) were plated into 48 -well plates. After $6 \mathrm{~h}$, the cells were treated with SKPin C1 at concentrations of 1,5 and $10 \mu \mathrm{M}$ for $48 \mathrm{~h}$. The expression levels of Skp2 and p2 $7^{\text {kipl }}$ were detected using western blot analysis and grey values were calculated, as presented in (C) (Skp2) and (D) (p27 $\left.7^{\mathrm{kip} 1}\right){ }^{* *} \mathrm{P}<0.01$ vs. control. Skp2, S-phase kinase-associated protein 2; SKPin C1, Skp2 inhibitor C1; shRNA, short hairpin RNA; N.C., negative control; Ctrl, control.
A

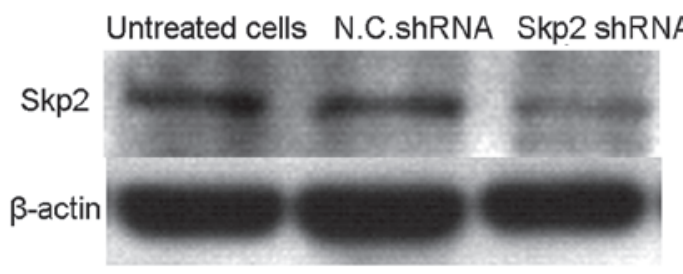

B

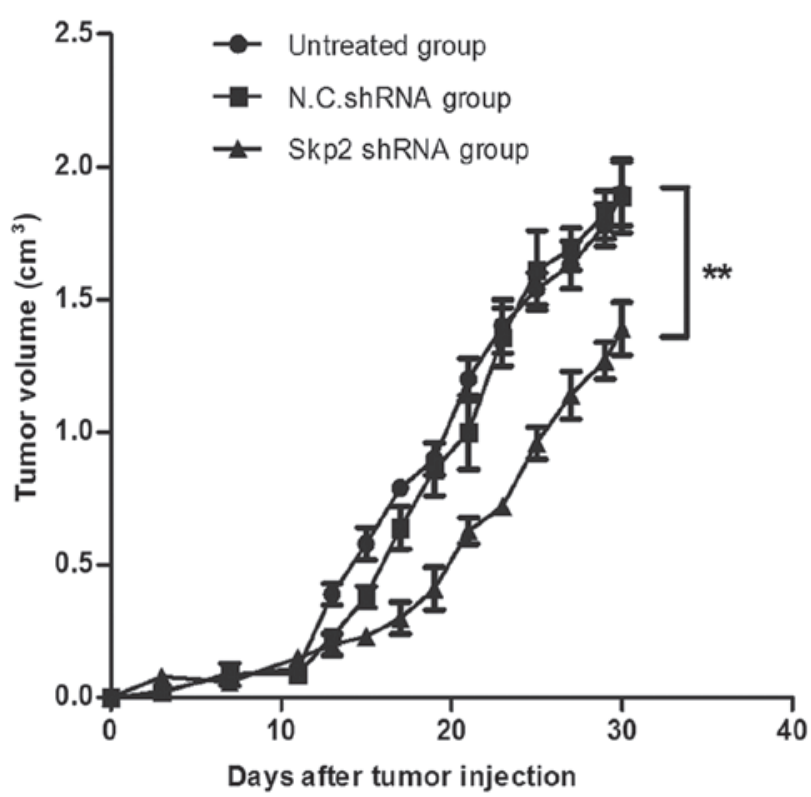

C
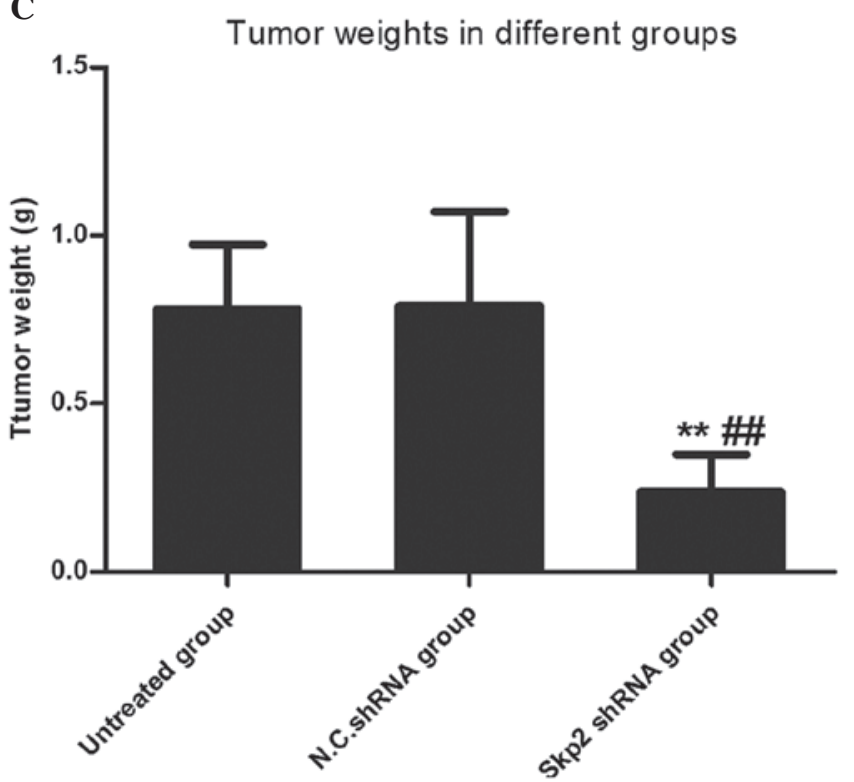

Figure 6. Interference with the endogenous expression of Skp2 inhibits cell growth in nude mice. (A) Human gastric cancer cells were stably transfected with Skp shRNA and N.C. shRNA, and the expression of Skp2 in the representative BGC-823 cells were detected using western blot analysis. The mice were injected subcutaneously with $5 \times 10^{5}$ stably-transfected gastric cancer cells to their flank area. After 30 days, the mice were sacrificed following the BGC-823 cell xenografting. Tumor (B) weights and (C) volumes were recorded. Data are presented as the mean \pm standard deviation. ${ }^{* *} \mathrm{P}<0.01$, compared with the N.C. shRNA-transfected mice. ${ }^{\# \#} \mathrm{P}<0.01$, compared with the untreated mice. Skp2, S-phase kinase-associated protein 2; SKP in C1, Skp2 inhibitor C1; shRNA, short hairpin RNA; N.C., negative control. 
examine the effects of Skp2 over time, $5 \mu \mathrm{M}$ was selected as an appropriate middle-range concentration for treatment of the human gastric cancer cells. As shown in Fig. 4C, the BGC-823 and MKN-45 cells were treated with $5 \mu \mathrm{M}$ of SKPin $\mathrm{C} 1$ for 24,48 and $72 \mathrm{~h}$, respectively. The results revealed that the proliferation of the BGC-823 cells and MKN-45 cells were significantly suppressed, compared with the untreated cells, in a time-dependent manner.

Transfection with Skp2 shRNA or treatment with SKPin C1 contributes to the accumulation of p27kipl in human gastric cancer cells. The present study also investigated the association between the levels of Skp2 and p2 $7^{\mathrm{kip} 1}$ in human gastric cancer cells. RNA interference technology and the specific inhibitor of Skp2 were used to interrupt the effect of Skp2 in the BGC-823 cells. As shown in Fig. 5A, the BGC-823 cells were transfected with Skp2 shRNA, to interfere with the expression of endogenous Skp2, for 48 and $72 \mathrm{~h}$. The Skp2-depleted BGC-823 cells showed marked accumulation of $\mathrm{p} 27^{\mathrm{kip} 1}$, compared with the N.C. shRNA-transfected BGC-823 cells. Consistent with the RNA interference experiment, the present study used increasing concentrations of Skp2 inhibitors to treat the BGC- 823 cells for $48 \mathrm{~h}$, The results revealed that the endogenous expression of Skp2 was not affected significantly by SKPin $\mathrm{C} 1$, however, the accumulation of $\mathrm{p} 27^{\mathrm{kip} 1}$ in the BGC-823 cells was significantly upregulated as the concentration of SKPin C1 increased. These data suggested that the Skp2-mediated degradation of $\mathrm{p} 27^{\mathrm{kip} 1}$ was inhibited by Skp2 shRNA transfection and Skp2 inhibition.

Interference with the endogenous expression of Skp2 inhibits tumor cell growth in nude mice. To further identify the inhibitory efficacy of Skp2 deletion in human gastric cancer cells, tumorigenicity experiments were performed in nude mice. The nude mice were randomly divided into three groups (>10 mice per group), as follows: Skp2 shRNA group, N.C. shRNA group and untreated group. The stably transfected BGC-823 cells were subcutaneously injected into the mice. As shown in Fig. 6, the tumor weight in the Skp2 shRNA group was significantly lower, compared with that in the N.C. shRNA group $(\mathrm{P}<0.01)$ and untreated group $(\mathrm{P}<0.01)$. This was consistent with the results obtained in the analysis of tumor volume in the tumorigenicity experiments $(\mathrm{P}<0.01$, vs. N.C. shRNA group).

\section{Discussion}

Gastric cancer is a common malignant disease, which represents a serious health problem worldwide $(29,30)$. Although there have been substantial advances in the treatment of gastric cancer, the prognosis of metastatic gastric cancer remains poor. There are two ways to improve this, one is to identify novel potential biomarkers of prognostic significance in the early stage of gastric cancer, and the other is to improve current understanding of the molecular biology of the progression of gastric cancer, which offers the potential to improve treatment options for curing the disease. In the present study, the expression of Skp2 in gastric cancer tissues was analyzed and compared with that in normal gastric tissues using bioinformatics methods. As expected, the expression levels of Skp2 were significantly higher in the gastric cancer tissues and gastric cancer cell lines, compared with the normal gastric tissues, which was confirmed and consistent with the results obtained from western blot analysis. Additionally, the positive rate of Skp2 was $87.2 \%$ in the gastric cancer tissue samples, which was significantly higher, compared with the positive rate of $5.6 \%$ in the normal gastric samples $(\mathrm{P}<0.01)$. The above data confirmed that Skp2 worked as an oncogene during the progression of gastric cancer.

The ubiquitin protein ligase, $\mathrm{SCF}^{\mathrm{Skp} 2}$, is important in the degradation of tumor suppressor genes, including p $27^{\mathrm{kip} 1}$ and p53, and is composed of Skp1, cullin 1, regulator of cullins 1/ RING box protein 1 and the F-box protein, Skp2 (31-33). Skp2 is the substrate-recognition subunit in the SCF ubiquitin-protein ligase complex $(34,35)$. In the present study, the endogenous expression of Skp2 and p27 $7^{\mathrm{kip} 1}$ were detected in tissue specimens from patients with gastric cancer, and the results showed that the expression of Skp2 was negatively correlated with the expression of $\mathrm{p} 27^{\mathrm{kip} 1}$ in the patients with gastric cancer. Furthermore, interference of the endogenous expression of Skp2 was induced using shRNA specific to human Skp2, and SKPin C1, the Skp2 inhibitor, was used to inhibit the involvement and function of Skp2 in human gastric cancer cells. The results demonstrated that inhibiting the involvement and function of Skp2 in BGC-823 and MKN-45 cells significantly inhibited the proliferation of human gastric cancer cells.

The above results were confirmed by performing in vivo experiments. The stably transfected gastric cancer cells were subcutaneously injected into nude mice. The tumor weights and tumor volumes in Skp2 shRNA group were significantly lower, compared with those in the N.C. shRNA group $(\mathrm{P}<0.01)$ and untreated group $(\mathrm{P}<0.01)$. This was consistent with the results obtained in the Skp2 interference experiments, suggesting that the antitumor activity was partly due to the accumulation of the tumor inhibitor protein, $\mathrm{p} 27^{\mathrm{kip} 1}$, which was induced by inhibiting or interfering with, the function of Skp2. Thus, Skp2 was shown to be a promising and effective drug target for the treatment of human gastric cancer.

\section{References}

1. Fu DG: Epigenetic alterations in gastric cancer (Review). Mol Med Rep 12: 3223-3230, 2015.

2. Afuwape OO, Irabor DO, Ladipo JK and Ayandipo B: A review of the current profile of gastric cancer presentation in the university college hospital Ibadan, a tertiary health care institution in the tropics. J Gastrointest Cancer 43: 177-180, 2012.

3. Tey J, Choo BA, Leong CN, Loy EY, Wong LC, Lim K, Lu JJ and Koh WY: Clinical outcome of palliative radiotherapy for locally advanced symptomatic gastric cancer in the modern era. Medicine (Baltimore) 93: e118, 2014.

4. Katai H: Function-preserving surgery for gastric cancer. Int J Clin Oncol 11: 357-366, 2006.

5. Ikeguchi M, Oka S, Gomyo Y, Tsujitani S, Maeta M and Kaibara N: Prognostic benefit of extended radical lymphadenectomy for patients with gastric cancer. Anticancer Res 20: 1285-1289, 2000.

6. Jiang S, Ge W, Zheng L and Chen G: Analysis of clinicopathological features and prognosis in 30 cases with multifocal gastric cancer. Zhonghua Wei Chang Wai Ke Za Zhi 18: 135-138, 2015 (In Chinese).

7. Cui H, Deng J, Liang H, Zhang R, Ding X, Pan Y, Wang B and Wu W: Advantage of $\mathrm{D} 2+$ lymph node dissection for distal advanced gastric cancer. Zhonghua Wei Chang Wai Ke Za Zhi 18: 127-130, 2015 (In Chinese). 
8. Almubarak MM, Laé M, Cacheux W, de Cremoux P, Pierga JY, Reyal F, Bennett SP, Falcou MC, Salmon RJ, Baranger B and Mariani P: Gastric metastasis of breast cancer: A single centre retrospective study. Dig Liver Dis 43: 823-827, 2011.

9. Karagulle M, Fidan E, Kavgaci H and Ozdemir F: The effects of environmental and dietary factors on the development of gastric cancer. BUON 19: 1076-1082, 2014.

10. Lee YY and Derakhshan MH: Environmental and lifestyle risk factors of gastric cancer. Arch Iran Med 16: 358-365, 2013.

11. Zuk K, Peczek L, Stec-Michalska K, Medrek M and Nawrot B: SATB1 expression in gastric mucosa in relation to Helicobacter pylori infection and family history of gastric cancer. Adv Med Sci 57: 237-243, 2012.

12. Zhao Q, Wang Y, Cao Y, Chen A, Ren M, Ge Y, Yu Z, Wan S, $\mathrm{Hu} \mathrm{A}, \mathrm{Bo} \mathrm{Q}$, et al: Potential health risks of heavy metals in cultivated topsoil and grain, including correlations with human primary liver, lung and gastric cancer, in Anhui province, Eastern China. Sci Total Environ 470-471: 340-347, 2014.

13. Shin JY, Kim HS, Lee KS, Kim J, Park JB, Won MH, Chae SW, Choi YH, Choi KC, Park YE and Lee JY: Mutation and expression of the p27KIP1 and p57KIP2 genes in human gastric cancer. Exp Mol Med 32: 79-83, 2000.

14. Bretones G, Acosta JC, Caraballo JM, Ferrándiz N, Gómez-Casares MT, Albajar M, Blanco R, Ruiz P, Hung WC, Albero MP, et al: SKP2 oncogene is a direct MYC target gene and MYC down-regulates p27 (KIP1) through SKP2 in human leukemia cells. J Biol Chem 286: 9815-9825, 2011.

15. Cen B, Mahajan S, Zemskova M, Beharry Z, Lin YW, Cramer SD, Lilly MB and Kraft AS: Regulation of Skp2 levels by the Pim-1 protein kinase. J Biol Chem 285: 29128-29137, 2010.

16. Zhang B, Ji LH, Liu W, Zhao G and Wu ZY: Skp2-RNAi suppresses proliferation and migration of gallbladder carcinoma cells by enhancing p27 expression. World J Gastroenterol 19: 4917-4924, 2013

17. Tsai YS, Lai CL, Lai CH, Chang KH, Wu K, Tseng SF, Fazli L, Gleave M, Xiao G, Gandee L, et al: The role of homeostatic regulation between tumor suppressor DAB2IP and oncogenic Skp2 in prostate cancer growth. Oncotarget 5: 6425-6436, 2014.

18. Huang H, Song Y, Wu Y, Guo N, Ma Y and Qian L: Erbin loss promotes cancer cell proliferation through feedback activation of Akt-Skp2-p27 signaling. Biochem Biophys Res Commun 463 370-376, 2015

19. Ben-Izhak O, Akrish S, Gan S and Nagler RM: Skp2 and salivary cancer. Cancer Biol Ther 8: 153-158, 2009.

20. Li B, Lu W, Yang Q, Yu X, Matusik RJ and Chen Z: Skp2 regulates androgen receptor through ubiquitin-mediated degradation independent of Akt/mTOR pathways in prostate cancer. Prostate 74: 421-432, 2014
21. Davidovich S, Ben-Izhak O, Shapira M, Futerman B and Hershko DD: Over-expression of Skp2 is associated with resistance to preoperative doxorubicin-based chemotherapy in primary breast cancer. Breast Cancer Res 10: R63, 2008.

22. Hao Z and Huang S: E3 ubiquitin ligase Skp2 as an attractive target in cancer therapy. Front Biosci (Landmark Ed) 20: 474-490, 2015.

23. Chan CH, Morrow JK, Zhang S and Lin HK: Skp2: A dream target in the coming age of cancer therapy. Cell Cycle 13: 679-680, 2014

24. Orlans FB: Case studies of ethical dilemmas: Animal Care and Use Committee. Lab Anim Sci 37 Spec No: 59-64, 1987.

25. Rowan AN: Animals, science, and ethics - Section IV. Ethical review and the animal care and use committee. Hastings Cent Rep 20: S19-24, 1990.

26. Stockert JC, Blázquez-Castro A, Cañete M, Horobin RW and Villanueva A: MTT assay for cell viability: Intracellular localization of the formazan product is in lipid droplets. Acta Histochem 114: 785-796, 2012.

27. Yilmaz Z, Dogan AL, Ozdemir O and Serper A: Evaluation of the cytotoxicity of different root canal sealers on L929 cell line by MTT assay. Dent Mater J 31: 1028-1032, 2012.

28. Wu C, Macleod I and Su AI: BioGPS and MyGene.info: Organizing online, gene-centric information. Nucleic Acids Res 41 (Database Issue): D561-D565, 2013.

29. Popiela T, Kulig J, Kolodziejczyk P and Sierzega M; Polish Gastric cancer study group: Long-term results of surgery for early gastric cancer. Br J Surg 89: 1035-1042, 2002.

30. Fejzo MS, Anderson L, Chen HW, Anghel A, Zhuo J, Anchoori R, Roden R and Slamon DJ: ADRM1-amplified metastasis gene in gastric cancer. Genes Chromosomes Cancer, 2015 (Epub ahead of print).

31. Wei Z, Jiang X, Qiao H, Zhai B, Zhang L, Zhang Q, Wu Y, Jiang H and Sun X: STAT3 interacts with Skp2/p27/p21 pathway to regulate the motility and invasion of gastric cancer cells. Cellular Signal 25: 931-938, 2013.

32. Yoon JH, Seo HS, Choi WS, Kim O, Nam SW, Lee JY and Park WS: Gastrokine 1 induces senescence and apoptosis through regulating telomere length in gastric cancer. Oncotarget 5: 11695-11708, 2014

33. Pavlides SC, Huang KT, Reid DA, Wu L, Blank SV, Mittal K, Guo L, Rothenberg E, Rueda B, Cardozo T and Gold LI: Inhibitors of SCF-Skp2/Cks1 E3 ligase block estrogen-induced growth stimulation and degradation of nuclear p27kip1: Therapeutic potential for endometrial cancer. Endocrinology 154: 4030-4045, 2013.

34. Pascal LE and Wang Z: Virtual drug design: Skp1-Skp2 inhibition targets cancer stem cells. Asian J Androl 15: 717-718, 2013.

35. Chan CH, Morrow JK, Li CF, Gao Y, Jin G, Moten A, Stagg LJ, Ladbury JE, Cai Z, Xu D, et al: Pharmacological inactivation of Skp2 SCF ubiquitin ligase restricts cancer stem cell traits and cancer progression. Cell 154: 556-568, 2013. 